\title{
Facile wet-chemical synthesis of differently shaped cuprous oxide particles and a thin film: Effect of catalyst morphology on the glucose sensing performance
}

\author{
C. Neetzel ${ }^{1,2,3^{*}}$, F. Muench ${ }^{1}$, T. Matsutani ${ }^{1,4}$, J.C. Jaud ${ }^{1}$, J. Broetz ${ }^{1}$, T. Ohgai ${ }^{2}$, W. Ensinger ${ }^{1}$
}

${ }^{1}$ Technical University of Darmstadt, Department of Materials Science, Alarich-Weiss-Strasse 2, 64287 Darmstadt, Germany

2 Nagasaki University, Faculty of Engineering, 1-14 Bunkyo-machi, 852-8521, Nagasaki, Japan

${ }^{3}$ JSPS Postdoctoral Fellow, Kojimachi 5-3-1, Chiyoda-ku, 102-0083, Tokyo, Japan

${ }^{4}$ Kinki University, Department of Electric \& Electronic Engineering, 3-4-1 Kowakae, Higashi-osaka, Osaka, 577-8502, Japan

*Corresponding Author: E-mail: Neetzel@ca.tu-darmstadt.de

Keywords: non-enzymatic glucose sensing, cuprite particles, wet-chemical reduction, self-assembly, electroless deposition

\begin{abstract}
In this work, different facile synthesis routes were developed to create cuprite-based catalyst systems for the amperometric detection of glucose, allowing us to evaluate the impact of important electrode fabrication parameters on the glucose sensing performance. Using homogenous precipitation routes based on a redox system, two differently shaped cuprite particles—skeletons and polyhedrons—could be obtained. Furthermore, a novel electroless deposition technique was introduced that does not require sensitization and activation pretreatments, allowing for the direct modification of the glassy carbon. This technique produced electrodes with dense thin film consisting of merged, octahedral cuprite crystals. Afterward, these materials were tested as potential catalysts for the electrochemical detection of glucose. While the catalyst powders obtained by precipitation required Nafion ${ }^{\circledR}$ to be attached to the electrode, the thin film synthesized using electroless plating could be realized with and without additive. Summarizing the results, it was found that Nafion $^{\circledR}$ was not required to achieve glucose selectivities typically observed for cuprite catalysts. Also, the type of catalyst application (direct plating versus ink drop coating) and the particle shape had a pronounced effect on the sensing performance. Compared to the thin film, the powder-type materials showed significantly increased electrochemical responses. The best overall performance was achieved with the polyhedral cuprite particles, resulting in a high sensitivity of $301 \mu \mathrm{A} \cdot \mathrm{mmol}^{-1} \mathrm{~cm}^{-2}$, a linear range up to $298 \mu \mathrm{mol} \cdot \mathrm{L}^{-1}$ and a limit of detection of $0.144 \mu \mathrm{mol} \cdot \mathrm{L}^{-1}$.
\end{abstract}




\section{Introduction}

In 2013, the World Health Organization published recent figures on persons suffering from diabetes. According to this report, over 347 million persons are afflicted with hyperglycemia and therefore need a continuous and accurate control of their blood sugar level by using a handy and reliable monitoring system [1]. Since the first establishment of an enzyme-based glucose sensor by Clark and Lyons in 1962, further improvements have led to three generations of blood glucose devices [2].

Nowadays, most commercially available biosensors are based on the glucose oxidase principle. However, these systems exhibit some disadvantages such as low stability, high cost of enzyme material and a complex immobilization process. Consequently, the demand for the development of new and suitable non-enzymatic electrocatalytic active electrodes has arisen in recent decades. New laboratory research on the topic involves the use of noble metals such as gold ( $\mathrm{Au})$ [3], platinum (Pt) [4], and alloys thereof [5,6]. However, these electrodes occasionally suffer from low selectivities, high costs and poisoning.

Some investigations also have been carried out with copper and its oxides, based on intensive studies of their intrinsic activity and the conversion mechanism [7,8]. In general, the usage of cuprite $\left(\mathrm{Cu}_{2} \mathrm{O}\right)$ benefits from its low oxidation potential in alkaline solutions that consequently leads to enhanced sensitivities compared to more noble metals, although the stability of the material lacks in acidic media.

Many publications describe the synthesis of copper oxide materials with different sizes and morphologies, such as cubes and spheres, and the application of these materials in the electrochemical detection of glucose [9-11]. However, most of these studies remain restricted to a single or few closely related catalyst types [12-14]. For example, the sensing performance of cuprite/copper octahedron in micrometer scale was evaluated according to [9]. In another publication, Reitz et al. described the synthesis of copper oxide microspheres with high surface areas [11]. Furthermore, the group of Zhang et al. presented the fabrication and characterization of a multiwalled carbon nanotube/cuprite network in 2012 [14]. On the other hand, Won and Stanciu compared four different types of catalyst morphologies, namely cubes, octahedron, truncated octahedron and hexapods [10]. Such kind of comparative work is important to obtain a basic understanding of the effect of catalyst morphologies and electrode preparation techniques on the sensing performance.

Commonly, electrodes for the detection of glucose are prepared by using catalyst powders in combination with Nafion ${ }^{\circledR}$ as an adhesive additive [11,13-15]. Several papers claim that, in addition to stabilizing the catalyst, Nafion ${ }^{\circledR}$ also is responsible for the catalyst selectivity, as it might repulse negatively charged, possibly interfering species such as ascorbic acid due to electrostatic forces [1315]. However, in these studies, no reference experiments without Nafion ${ }^{\circledR}$ were performed, which would be required to clearly describe the role of this additive.

In order to obtain cuprite particles with a specific morphology, different methods have been carried out (e.g., hydrothermal [16], sol-gel and electrodeposition techniques [17]). Wet-chemical methods 
possess many advantages due to low costs and feasibilities. Here, an accurate control of kinetic and thermodynamic parameters is one of the key considerations. Crucial factors include temperature, template agents such as surfactants, and concentration of the used chemicals. During the last few years, several studies focusing on diverse wet-chemical cuprite particle synthesis have been mostly based on the introduction of form-shaping agents [18].

Herein, we report two possible low-cost and easily-realizable routes for the shape-controlled synthesis of cuprite particles leading to well-defined shapes and without the need of form-shaping chemicals. The synthesis is carried out in aqueous solution under mild conditions and with $\alpha$-D-glucose as reducing agent. We show that, depending on the reaction time and the concentration ratio, it is possible to obtain different structures, namely skeletal and polyhedral particles. In this connection, we compare the effect of catalyst morphology to the glucose sensing performance.

Furthermore, we present a novel cuprite electroless deposition technique whereby the surface of the electrode is directly coated without the need of any pretreatment steps. The adhering films obtained with this method allow us to analyze the performance of well-defined cuprite catalysts in the electrooxidation of glucose in the absence of Nafion $^{\circledR}$. Although the obtained results of the sensing performance need to be improved in further studies, we herein present a basic concept for the design of future glucose electrodes by a direct electroless deposition method yielding to higher surface areas.

\section{Materials and Methods}

\subsection{Particle preparation}

Wet-chemical particle preparation was conducted by using the Fehling method [19]. An aqueous solution consisting of $12 \mathrm{mmol} \cdot \mathrm{L}^{-1} \mathrm{CuSO}_{4}$ (copper sulfate, Fluka purum p.a.), $14 \mathrm{mmol} \cdot \mathrm{L}^{-1}$ $\mathrm{KNaC}_{4} \mathrm{H}_{4} \mathrm{O}_{6}$ (potassium sodium tartrate, Sigma Aldrich) and $175.01 \mathrm{mmol} \cdot \mathrm{L}^{-1} \mathrm{NaOH}$ (sodium hydroxide, Sigma Aldrich) was heated to $90^{\circ} \mathrm{C}$ (Fehling I and II). Afterward, a solution (Fehling III) consisting of $4 \mathrm{mmol} \cdot \mathrm{L}^{-1} \mathrm{C}_{6} \mathrm{H}_{12} \mathrm{O}_{6}$ ( $\alpha$-D-glucose, Sigma Aldrich) was added in the same volume ratio of Fehling I+II and Fehling III: 1:1. Using this concentration composition, skeletal particles could be obtained. In the case of the preparation of polyhedral particles, the concentration of potassium sodium tartrate was increased to $28 \mathrm{mmol} \cdot \mathrm{L}^{-1}$, which yielded a concentration ratio of copper sulfate and potassium sodium tartrate of approximately 1:2.

The reaction time was fixed to 60 minutes for the preparation of skeletal particles and 120 minutes for the synthesis of polyhedron structures at a constant temperature of $90^{\circ} \mathrm{C}$.

Afterward, the obtained precipitation, indicated by a brick-red color, was collected, filtrated and washed several times with ultrapure water and then dried at room temperature for two days.

\subsection{Electroless thin film plating}

For the deposition of shape-controlled $\mathrm{Cu}_{2} \mathrm{O}$ thin films, electroless plating was used. The plating solution consisted of $25 \mathrm{mmol} \cdot \mathrm{L}^{-1} \mathrm{CuSO}_{4}$ pentahydrate (Fluka purum p.a.), $200 \mathrm{mmol} \mathrm{L}{ }^{-1} \mathrm{C}_{2} \mathrm{H}_{4}\left(\mathrm{NH}_{2}\right)_{2}$ (ethylenediamine, Roth, for synthesis) and $450 \mathrm{mmol} \cdot \mathrm{L}^{-1} \mathrm{CH}_{2} \mathrm{O}$ (formaldehyde, Fluka puriss. p.a.). The 
reaction started as the solution was heated close to boiling. Deposition was indicated by the formation of a light-colored, reddish film on the materials in contact with the heated solution (e.g., carbon and polymer substrates or the glass walls of the beaker used for plating). In contrast to the usual reactivity [20,21], no seeding step was required to initiate electroless plating; the film formation relied on heterogeneous, non-catalyzed nucleation [22]. A plating time of 10 minutes was applied. In general, the thin film could be removed mechanically (e.g. by the use of a tissue) on smooth surfaces. However, on rough surfaces the adhesion was greatly improved.

\subsection{Materials characterization}

For the X-ray diffraction (XRD) analysis, electroless plating was performed on polycarbonate foil. After the reaction, the polymer was dissolved with dichloromethane (Roth, $\geq 99.8 \%$ IR grade), and the deposit was isolated by centrifugation. Measurements were conducted with a diffractometer STOE STADI $\left(\lambda_{\text {Mo }}=0.0709 \mathrm{~nm}\right)$ in $\theta-2 \theta$ geometry.

The morphology and structure of the cuprite particles and the thin film were characterized by scanning electron microcopy (SEM) by using a high definition XL from Philips in a secondary electron modus of voltages from 15 up to $30 \mathrm{kV}$.

\subsection{Electrode preparation and electrocatalysis}

All catalysts were applied on a glassy carbon (GC) electrode of $3 \mathrm{~mm}$ diameter. In the case of the particulate catalysts, the electrode was modified by drop-coating with ethanolic particle suspensions, yielding a catalyst loading of approximately $0.8 \mathrm{mg}$. After drop coating, the catalyst powder was modified with diluted Nafion ${ }^{\circledR}$ (Dupont ${ }^{\mathrm{TM}}$, distributed by Ion Power, D520 solution 5\% alcohol) solution (1 part Nafion ${ }^{\circledR}$ solution, 120 parts ethanol). Excess solution was carefully removed with tissue paper, and the electrode was left to dry.

For the electrochemical experiments of the thin film, a glassy carbon electrode was used as substrate for deposition. Due to the good adhesion of the film to the electrode in alkaline medium, Nafion ${ }^{\circledR}$ addition was not required, and the cuprite-modified electrode could be directly used for sensing. For reference testing the film was immersed in a diluted Nafion ${ }^{\circledR}$ solution (1 part Nafion ${ }^{\circledR}$ solution, 120 parts ethanol).

All electrochemical measurements were performed in a typical three-electrode assembly (potentiostat: GAMRY Reference $600^{\mathrm{TM}}$ ) with $\mathrm{Hg} / \mathrm{HgSO}_{4}$ as reference and Ag-net as auxiliary electrode. The electrolyte consisted of $100 \mathrm{mM} \mathrm{NaOH}$. During the electrochemical performances, the solution was continuously rinsed with nitrogen gas. The cyclic voltammetric experiments were carried out in a potential range from -400 to $400 \mathrm{mV}$ versus $\mathrm{Hg} / \mathrm{HgSO}_{4}$ and a scanning rate of $10 \mathrm{mV} \cdot \mathrm{s}^{-1}$. The amperometric measurements were performed at a potential of $0.25 \mathrm{mV}$ versus $\mathrm{Hg} / \mathrm{HgSO}_{4}$ and a sampling rate of $0.05 \mathrm{~s}$.

\section{Results and Discussion}




\subsection{Synthesis of cuprite particles and thin film}

Particle preparation was realized by a simple wet-chemical precipitation technique. The precursor solution consisted of a deep blue cupric tartrate complex in alkaline solution. Depending on the concentration ratio between cupric ions and tartrate, the complex forms different coordinations having unequal stability constants [23]. The reducing agent $\alpha$-D-glucose was added to the precursor solution at higher temperatures in order to generate an increased amount of open-chained redox active glucose molecules.

To obtain cuprite particles with different morphologies, a variation of the concentration ratio between copper and tartrate, depending on the reaction time, was tested in two series. For a concentration ratio of 1:1, a brick-red precipitation could be observed after 60 minutes. As shown in Figure 1a, the precipitate consists of skeletal structures with a total dimension of $1.96 \pm 0.78 \mu \mathrm{m}$. The basis of the structure is composed of six sections of micro-rods in an octahedral arrangement. At rod-ends, an outgrowth is observed that yielded to a variation of the diameter along the rod axes ranging from $161 \pm 20 \mathrm{~nm}$ (center diameter) to $437 \pm 20 \mathrm{~nm}$ (outgrowth diameter). In general, the structures show a high shape-uniformity involving an extraordinary reproducibility of the synthesis process.

Applying a concentration ratio between copper and tartrate of approximately 1:2 leads to the formation of polyhedron particles of different dimensions after a reaction time of 80 minutes. Figure $1 \mathrm{~b}$ shows that the sample consists of polygons including cubes (size range: 590 to $680 \mathrm{~nm}$ ), octahedrons (size range: 800 to $1300 \mathrm{~nm}$ ) and truncated octahedrons (size range: 1460 to $1600 \mathrm{~nm}$ ) with altered distinctive facets. In general, the quantity of the octahedron morphology is relatively high compared to the cube shapes.

The skeleton and polyhedron presented here are representative morphologies that were obtained during the test series performance. First, investigations (concentration ratio of copper ions and tartrate: 1:1) showed a transformation of the skeleton (Figure 1a) to polyhedral shapes at reaction times more than 60 minutes. However, these particles were shaped like polygons, with indentations at the edges and on the facings.

According to Prabahkaran and Murugan [24], the skeletal morphology can be explained by a fast growth of the $\{100\}$ facet due to the higher surface energy in comparison to the $\{110\}$ and $\{111\}$ directions. In addition, nucleation depends on the type of diffusion growth, which is influenced by the concentration of cupric ions, tartrate, hydroxide ions, and open-chain form of D-glucose.

As previously mentioned, a higher tartrate concentration led to the formation of different coordinated copper tartrate complexes in the precursor solution. Simultaneously, the amount of free copper ions, which are directly reduced to cuprite by D-glucose, was decreased. For this reason, different shapes were observed in the second reaction series. Under these conditions, a perfect crystal growth without the occurrence of dendritic branches could be observed [19]. In addition, for both reaction series, tartrate and D-glucose itself may have acted as form-shaping agents during the wet-chemical synthesis [25]. 
According to XRD measurements (see Figure 2), skeletal and polyhedron structures consists of pure cuprite without other crystalline impurities (PDF 74-1230). Additionally, a new electroless plating bath allowing the deposition of cuprite thin films was introduced. XRD measurements show the formation of a pure cuprite material as depicted in Figure 2. The thin film consists of interconnected octahedral-shaped particles with a size range of a few $100 \mathrm{~nm}$ (see Figure 3).

As an additional benefit to the observed shape control, no catalyst seeds were required to initiate deposition; different materials such as polymers, carbon and glass were covered with cuprite films by simple immersion in the plating bath. Therefore, pretreatment steps such as sensitization and activation [20] could be omitted, allowing facile and direct substrate modification. The presence of catalytically active noble metal nanoparticles, which are usually employed as plating seeds [20,26], was not required. Thus, contributions to the sensing performance of the thin film were avoided, ensuring the comparability of the three cuprite catalysts used in this study. It should be noted that, although no seeding was performed, a very dense coverage of the substrate with cuprite crystals could be achieved. This clearly outperformed the nucleation density of the other cuprite plating protocols $[20,27]$ and provided a large catalyst surface area.

\subsection{Amperometric sensing performance of glucose}

In order to determine the electrochemical activities of the cuprite skeletons/Nafion ${ }^{\circledR}$, polyhedrons/Nafion ${ }^{\circledR}$, and thin film, cyclovoltammetry measurements were carried out in a potential range from $-400 \mathrm{mV}$ to $400 \mathrm{mV}$ versus $\mathrm{Hg} / \mathrm{HgSO}_{4}$ in a pure sodium hydroxide solution that also contained $6 \mathrm{mmol}$ glucose. Whereas the polyhedron and skeleton structures were attached to the electrode with Nafion ${ }^{\circledR}$ solution (see experimental section), the electrolessly plated thin film could be utilized directly. In a reference experiment, an unmodified carbon rod was used.

As shown in Figure 4a, cyclic voltammogram measurements in pure sodium hydroxide solution shows a slight increase in the current density in a region from $100 \mathrm{mV}$ to $400 \mathrm{mV}$ versus $\mathrm{Hg} / \mathrm{HgSO}_{4}$, which can be explained by a partial oxidation as well as the formation of mixed hydroxides of the cuprite material [28]. Furthermore, it has been described that, at potentials more than $400 \mathrm{mV}$ versus $\mathrm{Ag} / \mathrm{AgCl}$, an oxidation of $\mathrm{Cu}^{2+}$ to $\mathrm{Cu}^{3+}$ occurs [29], while the cathodic peak can be attributed to the reduction of $\mathrm{Cu}^{3+}$. The sudden increased current density at a potential of about $350 \mathrm{mV}$ versus $\mathrm{Hg} / \mathrm{HgSO}_{4}$ is connected with a complete oxidation of cuprite. The catalytic inactivity of the skeleton and polyhedron structures in pure sodium hydroxide solution proves that there is no negative influence of D-glucose, which was used during the particle synthesis, on the sensing performance.

As shown in Figure 4b, cyclic voltammetry measurements shows a plateau in a clearly definable potential range from 150 to $300 \mathrm{mV}$ versus $\mathrm{Hg} / \mathrm{HgSO}_{4}$, which can be attributed to a glucose oxidation. According to the literature, the exact mechanism of the glucose oxidation is still unknown. Marioli and Kuwana [8] proposed that the conversion is catalyzed by a $\mathrm{Cu}^{3+}$ species that is formed on the surface of the electrode at potentials higher than $600 \mathrm{mV}$ versus $\mathrm{Ag} / \mathrm{AgCl}$, and which acts as an electron transmitter. Simultaneously, glucose is deprotonated to the endiol form under isomerization in alkaline 
solution and adsorbs to the catalytic active surface. In contrast to the conventional glucose oxidation (e.g., by using enzymatic glucose catalysts) that suggests the formation of gluconic acid, C-C bond cleavages take place. Further studies, in which copper-catalyzed oxidation products of different carbohydrates were analyzed by NMR and capillary electrophoresis measurements, found that the oxidation takes place under formation of carbonate and formate without any other side or intermediate products [30]. At lower potentials it is suggested that the 1,2 endiol form can be oxidized by $\mathrm{Cu}^{+}$under formation of glyculosonic acid, which subsequently generates smaller derivates by C-C bond cleavages [8].

The peak current of the electrodes modified with skeletons/Nafion ${ }^{\circledR}$ and polyhedron/Nafion ${ }^{\circledR}$ is three times higher than the thin film, which underlines their good electrocatalytic activity in connection with a good double-layer capacitance. According to these results, all three types of cuprite structures exhibit the highest catalytic activity in the range of $250 \mathrm{mV}$ versus $\mathrm{Hg} / \mathrm{HgSO}_{4}$. Therefore, the following sensitivity and selectivity investigations were carried out using this potential.

For sensitivity determination, amperometric measurements were realized by successive addition of glucose of different amounts starting from $1 \mu \mathrm{mol}$ to $1 \mathrm{mmol}$. Figure 5 depicts well-defined steps after each glucose adjunction for the polyhedron/Nafion ${ }^{\circledR}$ catalyst. Especially at lower glucose concentration, the signal noise is small and the stages are well-formed (compare insets Figure 5a and b), which indicates a complete sugar oxidation. The noise increases at higher glucose concentrations, especially when a total glucose concentration of $298 \mu \mathrm{mol} \cdot \mathrm{L}^{-1}$ is reached. This phenomenon may relate to the calibration curve that describes the current increase as a function of the overall glucose concentration (Figure 6). In the range of $1.2 \mu \mathrm{mol} \cdot \mathrm{L}^{-1}$ to $298 \mu \mathrm{mol} \cdot \mathrm{L}^{-1}$, the polyhedron/Nafion ${ }^{\circledR}$ catalyst exhibit a good linearity (slope of regression equation: $0.30096, \mathrm{R}^{2}=0.998$ ) with a sensitivity of 300.96 $\mu \mathrm{A} \cdot \mathrm{mmol}^{-1} \cdot \mathrm{cm}^{-1}$. According to Figure 5, the slopes of the electrodes modified with skeleton/Nafion ${ }^{\circledR}$ and thin film are comparably lower. Furthermore, the skeleton/Nafion ${ }^{\circledR}$ catalyst shows two linear ranges from $2.9 \mu \mathrm{mol} \cdot \mathrm{L}^{-1}$ to $20.0 \mu \mathrm{mol} \cdot \mathrm{L}^{-1}$ (slope of regression equation: $0.26228, \mathrm{R}^{2}=0.997$ ) and from $57.7 \mu \mathrm{mol} \cdot \mathrm{L}^{-1}$ to $224 \mu \mathrm{mol} \cdot \mathrm{L}^{1}$ (slope of regression equation: 0.10918 ), such that sensitivities of 262.28 $\mu \mathrm{A} \cdot \mathrm{mmol}^{-1} \cdot \mathrm{cm}^{-2}$ and $109.18 \mu \mathrm{A} \cdot \mathrm{mmol}^{-1} \cdot \mathrm{cm}^{-2}$ (see Figure 5) can be calculated, respectively.

Compared to the polyhedron/Nafion ${ }^{\circledR}$ catalyst, the thin film electrode exhibits an approximately eight times lower sensitivity of $49.8 \mu \mathrm{A} \mathrm{mmol}{ }^{-1} \cdot \mathrm{cm}^{-2}$ (slope of regression equation: 0.00498 ) in the linear range from $29.5 \mu \mathrm{mol} \cdot \mathrm{L}^{-1}$ to $380.6 \mu \mathrm{mol} \cdot \mathrm{L}^{-1}$.

The limit of detection (LOD) was calculated by applying the 3-sigma method of the ground signal [31] in pure sodium hydroxide solution and using obtained sensitivities of all three types of catalysts. As a result, the LOD for the polyhedron/Nafion ${ }^{\circledR}$ catalyst is $0.144 \mu \mathrm{mol} \cdot \mathrm{L}^{-1}$, for the skeleton/ $\mathrm{Nafion}{ }^{\circledR} 0.564$ $\mu \mathrm{mol} \cdot \mathrm{L}^{-1}$ and for the cuprite thin film $19.48 \mu \mathrm{mol} \cdot \mathrm{L}^{-1}$.

Additionally, we measured the response time $t_{r}$ by determining the time difference between the instantaneous glucose addition and after achieving a 95\% response. As a result, $t_{r}=3 \mathrm{~s}$ can be 
measured for the skeleton structures and the thin film. The $t_{r}$ value for the catalyst composed of polyhedron structures is $4 \mathrm{~s}$.

Table 1 summarizes obtained sensitivities, LOD values, and response times $t_{r}$ for all three types of catalysts. According to these results, polyhedron/Nafion ${ }^{\circledR}$ electrodes have the highest sensitivity and the lowest LOD. As previously mentioned, the polyhedron sample consists of differently exposed facets, namely $\{111\}$ (octahedron and truncated octahedron) and $\{100\}$ (truncated octahedron and cubes). It has been described that the surface energy of $\{111\}$ is comparably higher due to the presence of dangling $\mathrm{Cu}$ bonds and, therefore, this facet is positively charged [32]. On the other hand, the $\{100\}$ surface of the closed packed cubic structure is dominated by saturated $\mathrm{Cu}$ and $\mathrm{O}$ atoms such that the contribution of cubic morphologies to the catalytic activity is theoretically decreased. The phenomenon of a higher catalytic activity of octahedrons compared to cubes has been described previously [33,34].

Considering the higher relative quantity and sizes of the truncated octahedron of the polyhedron sample, it can be assumed that this morphology made the highest relative contribution to an enhanced catalytic activity. In comparison to polyhedron particles, skeleton structures exhibit a slightly lower sensitivity and a higher LOD. This phenomenon can be explained by a poor attachment of the structures on the GC electrode, resulting in a decreased electron transfer that may partly compensated by Nafion ${ }^{\circledR}$ [35]. In this connection, a direct comparison to the cuprite thin film, which was grown directly on the GC electrode, could be made. Unfortunately, the sensitivity and LOD of the thin film is not in range for a commercially available glucose sensor device described in the literature (normal physiological glucose concentration: $5.5 \mathrm{mM}$ ) [30,36]. However, the results are promising for a basic understanding of the future electrode design for two reasons: First, it is possible to carry out a direct electrode modification resulting in a nanostructured surface by a simple surface wrinkling process. The adhesion of the thin film on the GC electrode is comparable to that of catalysts based on cuprite particle/Nafion ${ }^{\circledR}$. This deposition technique enables the specific construction of an electrode with higher surface areas [37].

Second, the effect of Nafion ${ }^{\circledR}$ on glucose sensing performance was examined. According to Figure 7 the ground signal decreases gradually from polyhedron/Nafion ${ }^{\circledR}\left(\sim 42 \mu \mathrm{A} \cdot \mathrm{cm}^{2}\right.$, Figure 7a), skeleton/Nafion ${ }^{\circledR}\left(\sim 33 \mu \mathrm{A} \cdot \mathrm{cm}^{2}\right.$, Figure 7b), thin film $\left(\sim 9 \mu \mathrm{A} \cdot \mathrm{cm}^{2}\right.$, Figure $\left.7 \mathrm{c}\right)$ to thin film/Nafion ${ }^{\circledR}(\sim 4$ $\mu \mathrm{A} \cdot \mathrm{cm}^{2}$, Figure $\left.7 \mathrm{~d}\right)$. Thus, it can be assumed that Nafion ${ }^{\circledR}$ negatively influences the electrochemical performance by blocking active sites of the cuprite thin film catalyst.

Choi et al. analyzed high length-to-diameter aspect ratio Pt nanowires and compared catalytic mass activities with and without the use of Nafion ${ }^{\circledR}$. It could be verified that Nafion ${ }^{\circledR}$ negatively influences the electrochemical performance owing to a strong agglomeration of the nanowires in connection with a loss of the catalyst stability [38].

Comparing our results with other pure $\mathrm{Cu}_{2} \mathrm{O}$ materials (see Table 1), we can conclude that especially the polyhedron and the skeleton structures exhibit an excellent sensitivity, although the linear ranges 
are slightly lower. Furthermore, it can be noticed that $\mathrm{Cu}_{2} \mathrm{O}$ composite materials such as $\mathrm{Cu}_{2} \mathrm{O} / \mathrm{Carbon}$ [43] has a highly increased catalytic activity. For this reason, basic comparative studies of the morphology helped to develop non-enzymatic glucose sensors when adapting the results to the listed composite materials.

For the practical use of enzyme-free glucose sensors, a major issue is to analyze electroactive species that coexist in the human blood serum. For selectivity determination, the current response after successive addition of $100 \mu \mathrm{mol}$ glucose followed by urea, fructose and ascorbic acid (each $10 \mu \mathrm{mol}$ ) was measured. According to Figure 8, the current increase that followed after glucose addition was normalized to 1 unit for a better comparison between the three types of electrodes. Skeleton/Nafion ${ }^{\circledR}$ and polyhedron/Nafion ${ }^{\circledR}$ structures produce no significant signals after the addition of urea. A small current increase in correlation with fructose and ascorbic acid can be observed. Contrariwise, the thin film shows a small current increase only after addition of urea and fructose.

\section{Conclusion}

This report summarizes the synthesis method of cuprite particles with different morphologies by using homogenous precipitation. Without the need of surfactants, we achieved a morphology control by changing the concentration ratio between copper ions and tartrate of the precursor solution, dependent on the reaction time. Pure $\mathrm{Cu}_{2} \mathrm{O}$ polyhedron and skeleton structures were obtained in a high quantity. In combination with Nafion ${ }^{\circledR}$, both types of shape were tested as catalysts for the oxidation of glucose. An improved sensitivity of $300.96 \mu \mathrm{A} \cdot \mathrm{mmol}^{-1} \mathrm{~cm}^{-2}$ could be obtained for the polyhedron particles.

Additionally, the sensing performance was compared to a self-adhering cuprite thin film on the GC electrode material. Contrary to previous reports, Nafion ${ }^{\circledR}$ was not required to obtain the typical observed sensitivity toward glucose. Moreover, the presence of this additive significantly decreased the ground signal of the system, which was probably caused by mass transport limitations introduced by covering the catalyst structures with a non-active material. Therefore, enzyme-free glucose sensing setups should aim to avoid the use of Nafion ${ }^{\circledR}$ and to search for alternative catalyst attachment methods. For future work, it would be interesting to combine the favorable characteristics of the electroless deposition reaction with an electrically conducting, high-surface-area support in order to compensate for the reduced amount of catalyst deposited with this method.

\section{Acknowledgement}

This work was partially supported by the Beilstein Institute Frankfurt/Main within the project NanoMag. Additionally the authors thank to the Japanese Society for the Promotion of Science.

\section{References}

[1] http://www.who.int/diabetes/en/

[2] J. Wang, Electrochemical Glucose Biosensors, Chem. Rev. 108 (2008) 814-825. 
[3] Y. Bai, W. Yang, Y. Sun, C. Sun, Enzyme-free glucose sensor based on a three-dimensional gold film electrode, Sens. Actuators B 134 (2008) 471-476.

[4] L.-Q. Rong, C. Yang, Q.-Y. Qian, X.-H. Xia, Study of the nonenzymatic glucose sensor based on highly dispersed Pt nanoparticles supported on carbon nanotubes, Talanta 72 (2007) 819-824.

[5] Y.Bai, Y. Sun, C. Sun, Pt-Pb nanowire array electrode for enzyme-free glucose detection, Biosens. Bioelectron. 24 (2008) 579-585.

[6] P. Holt-Hindle, S. Nigro, M. Asmussen, A. Chen, Amperometric glucose sensor based on platinum-iridium nanomaterials, Electrochem. Commun. 10 (2008) 1438-1441.

[7] Y.B. Vassilyev et al., Kinetics and mechanism of glucose electrooxidation on different electrodecatalysts. PartII. Effect of the nature of the electrode and the electrooxidation mechanism, J.

Electroanal. Chem. 196 (1985) 127-144.

[8] J.M. Marioli and T. Kuwana, Electrochemical characterization of carbohydrate oxidation at copper electrodes, Electrochim. Acta. 37 (1992) 1187-1197.

[9] L. Wang, J. Fu, H. Hou, Y. Song, A facile strategy to prepare $\mathrm{Cu}_{2} \mathrm{O} / \mathrm{Cu}$ electrode as a sensitive enzyme-free glucose sensor, Int. J. Electrochem. Sci. 7 (2012) 12587-12600.

[10] Y.-H. Won and L.A. Stanciu, $\mathrm{Cu}_{2} \mathrm{O}$ and $\mathrm{Au} / \mathrm{Cu}_{2} \mathrm{O}$ particles: Surface properties and applications in glucose sensing, Sensors 12 (2012) 13019-13033.

[11] E. Reitz, W. Jiu, M. Gentile, Y.Wang, Y. Lei, CuO nanospheres based nonenzymatic glucose sensor, Electroanal. 22 (2008) 2482-2486.

[12] J. Huang, Z. Dong, Y. Li, J. Wang, H. Yang, S. Li, S. Guo, J. Jin, R. Li, High performance nonenzymatic glucose biosensor based on copper nanowires-carbon nanotube hybrid for intracellular glucose study, Sens. Act. B 182 (2013) 618-624.

[13] Y. Zhao, J. Zhao, Y. Li, D. Ma, S. Hou, L. Li, X. Hao, Z. Wang, Room temperature synthesis of 2D CuO nanoleaves in aqueous solution, Nanotechn. 22 (2011) 115604-115613.

[14] P. Zhang, L. Zhang, H. Cai, C.Wang, A novel non-enzyme hydrogen peroxide sensor based on an electrode modified with carbon nanotube-wired CuO nanoflowers, Microchhim. Acta 176 (2012) 137142.

[15] S. Hrapovic, Y. Liu, K.. Male J.H.T. Luong, Electrochemical Biosensing Platforms Using Platinum Nanoparticles and Carbon Nanotubes, Anal. Chem. 76 (2004) 1083-1088.

[16] A.N. Tsvigunov, L.A. Frolova, V.G. Khotin, Detonation synthesis of cuprite with a cubic facecentered lattice (a review). Glas and Ceram. 60 (2003) 347-350.

[17] J. Xue, W. Liang, X. Liu, Q. Shen, B. Xu., Crystallization behavior and formation mechanism of dendrite $\mathrm{Cu}_{2} \mathrm{O}$ crystals, Cryst. Eng. Comm. 14 (2012) 8017-8022.

[18] C.-H. Kuo and M.H. Huang, Morphologically controlled synthesis of $\mathrm{Cu}_{2} \mathrm{O}$ nanocrystals and their properties, Nano Today, 5 (2010) 106-116.

[19] S. Hacialioglu, F. Meng, S. Jin, Facile and mild solution synthesis of Cu2O nanowires and nanotubes driven by screw dislocations, Chem. Commun. 48 (2012) 1174-1176. 
[20] M. D. Susman, Y. Feldman, A. Vaskevich, I. Rubinstein, Chemical deposition and stabilization of plasmonic copper nanoparticle films on transparent substrates, Chem. Mater. 24 (2012) 2501-2508.

[21] F. Muench, S. Lauterbach, H.-J. Kleebe, W. Ensinger, Deposition of nanofilms inside a polymer template: formation of metal nanotubes, e-J. Surf. Sci. Nanotechn. 10 (2012) 578-584.

[22] K.P. Pernstich, M. Schenker, F. Weibel, A. Rossi, W.R. Caseri, Electroless plating of ultrathin films and mirrors of platinum nanoparticles onto polymers, Metals, and Ceramics, ACS Appl. Mater. Interfaces 2 (2010) 639-643.

[23] N.D. Jespersen, Novel copper-tartrate coordination compound, Anal. Let. 5 (1972) 497-508.

[24] G. Prabhakaran and Ramaswamy Murugan, Synthesis of Cu2O microcrystals with morphological evolution from octahedral to microrod through a simple surfactant-free chemical route, Cryst. Eng. Commun. 14 (2012) 8338-8341.

[25] J.C. Ballesteros, E. Chainet, P. Ozil, Y. Meas, G. Trejo, Electrodeposition of copper from noncyanide alkaline solution containing tartrate, Int. J. Electrochm. Sci. 6 (2011) 2632-2651.

[26] F. Muench, U. Kunz, H.F. Wardenga, H.-J. Kleebe, W. Ensinger, Metal nanotubes and nanowires with rhombohedral cross-section electrolessly deposited in mica templates, Langmuir 30 (2014) 10878-10885.

[27] M. D. Susman, Y. Feldman, A. Vaskevich, I. Rubinstein, Chemical deposition of $\mathrm{Cu}_{2} \mathrm{O}$ nanocrystals with precise morphological control, ACS Nano 8 (2014) 162-174.

[28] M.R. Gennero De Chialvo, S.L. Marchiano, A.J. Arvia, The mechanism of copper in alkaline solutions, J. Appl. Electrochem. 14 (1984) 165-175.

[29] H.-X. Wu, W.-M. Cao, Y. Li, G. Liu, Y. Wen, H.-F. Yang, S.-P. Yang, In-situ growth of copper nanoparticles on multiwalled carbon nanotubes and their application as non-enzymatic glucose sensor materials, Electrochim. Acta 55 (2010) 3734-3740.

[30] G.S. Wilson and R. Gifford, Biosensors for real-time in-vivo measurements. Biosens. Bioelectron. 20 (2005) 2388-2403.

[31] S. Borgmann, A. Schulte, S. Neugebauer, W. Schuhmann, Amperometric Biosensors, in: R.C.

Alkire, D.M. Kolb, J. Lipkowski (Eds.), Advances in Electrochemical Science and Engineering, WILEY-VCH Verlag GmbH \& Co. KGaA, Weinheim, 2011, pp.1-84

[32] S. Sun and Z. Yang, Recent advances in tuning crystal facets of polyhedral cuprous oxide architectures, RSC Advances, 4 (2014) 3804-3822.

[33] Q. Li, P. Xu, B. Zhang, H. Tsai, S. Zheng, G. Wu, H.-L. Wang, Structure-dependent electrocatalytic properties of $\mathrm{Cu}_{2} \mathrm{O}$ nanocrystals for oxygen reduction reaction, J. Phys. Chem. C, 117 (2013) 13872-13878.

[34] C.-H. Kuo and M.H. Huang, Facile synthesis of $\mathrm{Cu}_{2} \mathrm{O}$ nanocrystals with systematic shape evolution from cubic to octaedral structures, J. Phys. Chem. C, 112 (2008) 18355-18360.

[35] L. Zhang, ,Y. Ni, H. Li, Addition of porous cuprous oxide to a Nafion film strongly improves the performance of nonenzymatic glucose sensor, Microchim. Acta, 171 (2010) 103-108. 
[36] D.C. Klonoff, Continous Glucose Monitoring, Diabetes Care, 28 (2005) 1231-1239.

[37] S. Du, A Facile Route for Polymer Electrolyte Membrane Fuel Cell Electrodes with in situ Grown Pt Nanowires, J. Power Sources, 195 (2010) 289-292.

[38] S.M Choi, J.H. Kim, J.Y. Jung, E.Y. Yoon, W. B. Kim, Pt nanowires prepared via a polymer template method: its promise toward high Pt-loaded electrocatalysis for methanol oxidation, Electrochim. Acta, 53 (2008) 5804-5811.

[39] Y. Qian, F. Ye, J. Xu, Z.-G. Le, Synthesis of cuprous oxide $\left(\mathrm{Cu}_{2} \mathrm{O}\right)$ nanoparticles/graphene composite with an excellent electrocatalytic activity towards glucose, Int. J. Electrochem. Sci., 7 (2012) 10063-10073.

[40] X. Zhang, G. Wang, W. Zhang, Y. Wie, B. Fang, Fixure-reduce method for the synthesis of $\mathrm{Cu}_{2} \mathrm{O} / \mathrm{MWCNTs}$ nanocomposites and its application as enzyme-free glucose sensor, Biosens. Bioelectron. 24 (2009) 3395-3398.

[41] S. Felix, P. Kollu, B.P.C. Raghupathy, S.K. Jeong, A.N. Nirmala Grace, Electrocatalytic activity of $\mathrm{Cu}_{2} \mathrm{O}$ nanocubes-based electrode for glucose oxidation, J. Chem. Sci., 126 (2014) 25-32. [42] D.-L. Zhou, J.-J. Feng, L.-Y. Cai, Q.-X. Fang, J.-R. Chen, A.-J. Wang, Facile synthsis of monodisperse porous $\mathrm{Cu}_{2} \mathrm{O}$ nanospheres on reduced graphene oxide for non-enzymatic amperometric glucose sensing, Electrochim. Acta, 113 (2014) 103-108.

[43] K.M. El Khatib and R.M. Abdel Hameed, Development of Cu2O/carbon vulcan XC-72 as nonenzymatic sensor for glucose determination, Biosens. Bioelectron. 26 (2011) 3542-3548. 


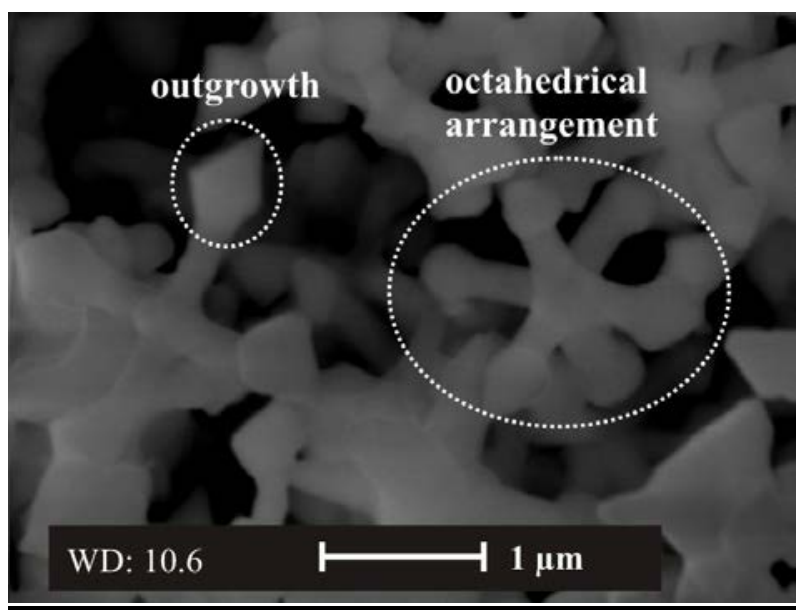

Figure 1a): Skeletal structures obtained by wet-chemical homogeneous precipitation (concentration ratio between copper and tartrate: 1:1; reaction time: 60 minutes) with a total dimension of $1.96 \pm 0.78$ $\mu \mathrm{m}$

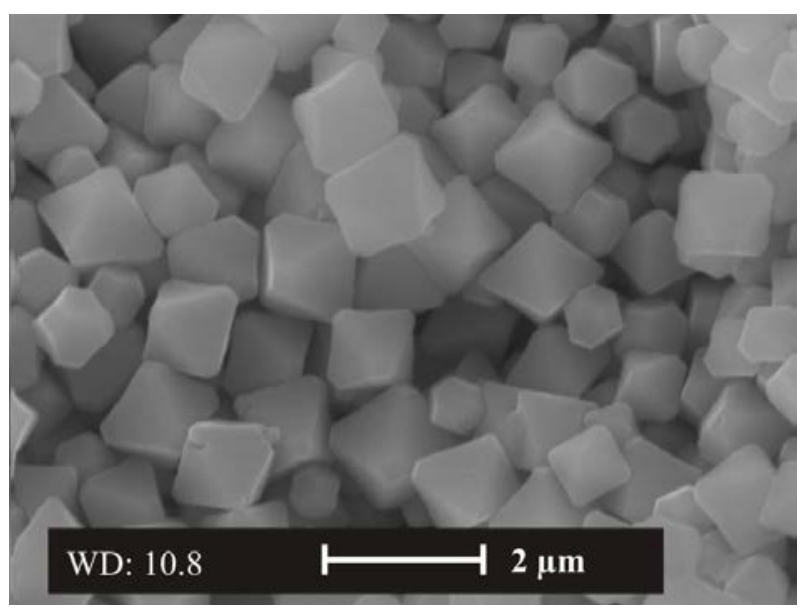

Figure 1b): Polyhedron structures obtained by wet-chemical homogeneous precipitation (concentration ratio between copper and tartrate: 1:1; reaction time: 120 minutes): The sample mainly consisted of truncated octahedron with average dimension 1.46 to $1.60 \mu \mathrm{m}$ 


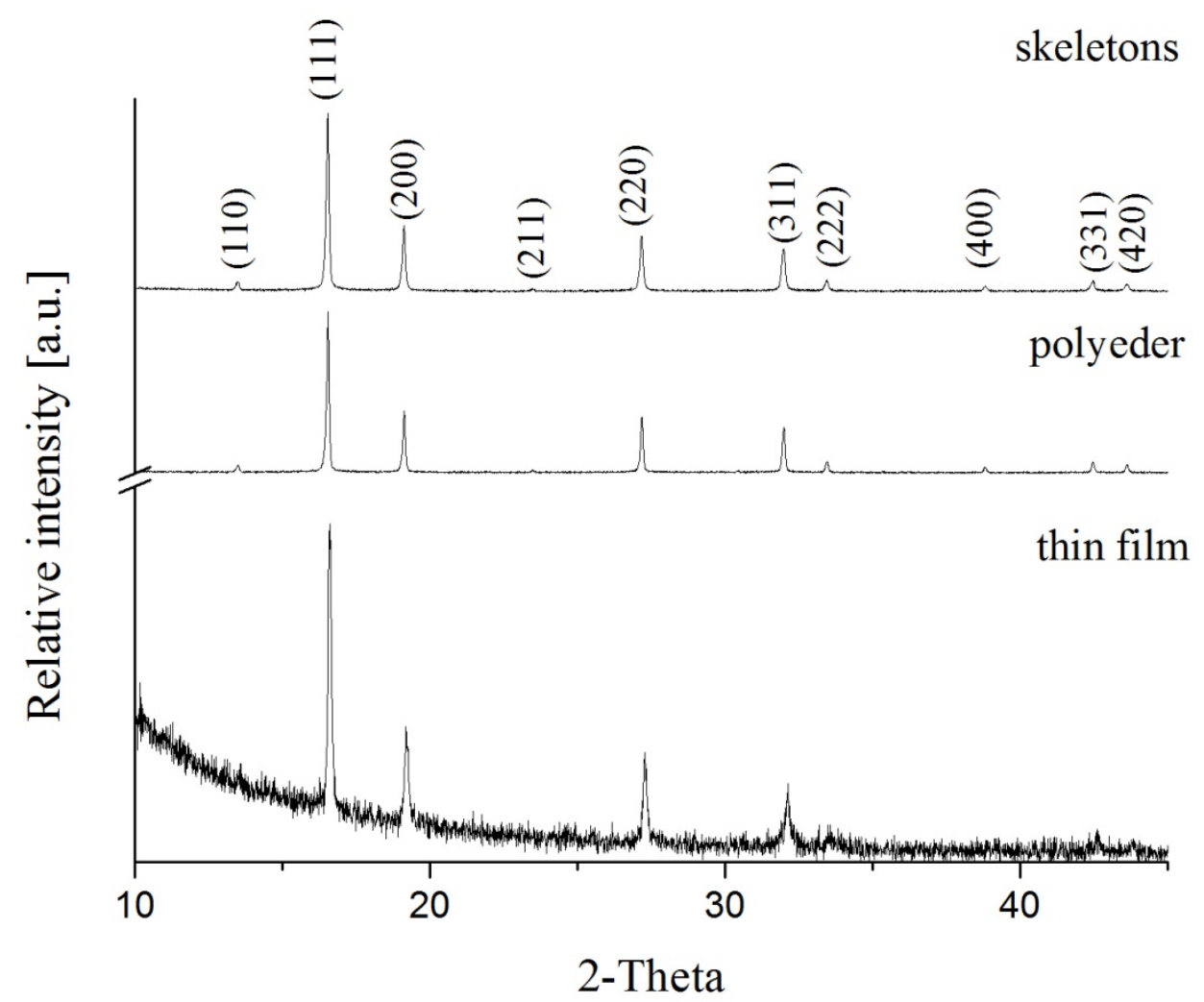

Figure 2): X-ray diffraction pattern of skeleton and polyhedron structures obtained by homogeneous precipitation and the thin film obtained by electroless deposition

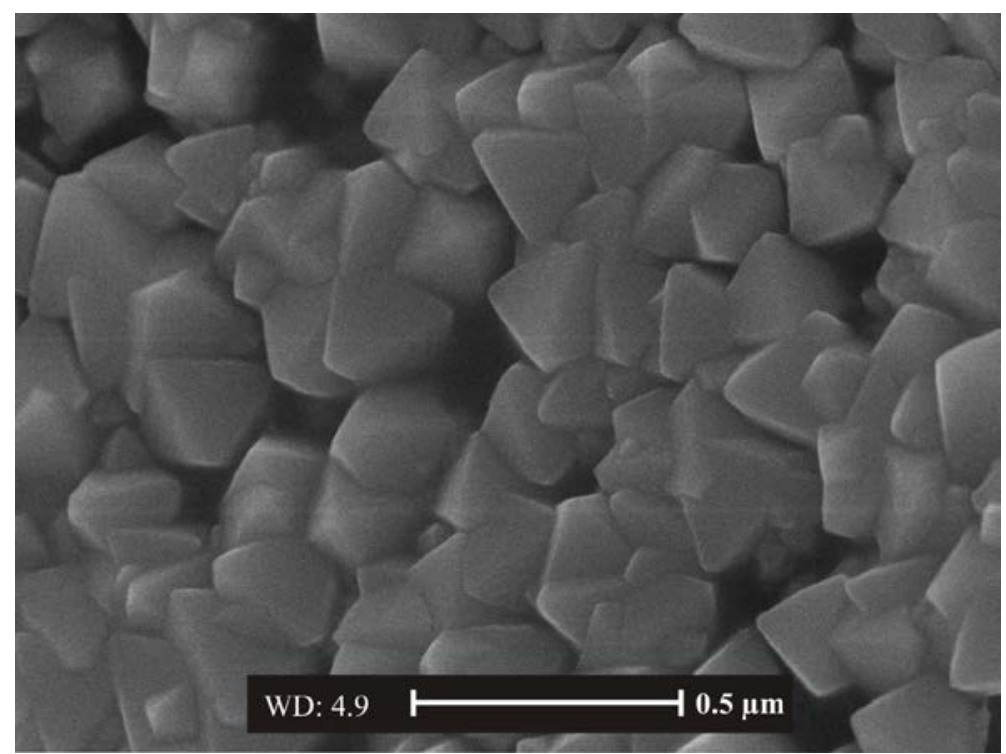

Figure 3): Thin film consisting of dense interconnected octahedron structures obtained by electroless plating on a glassy carbon surface 

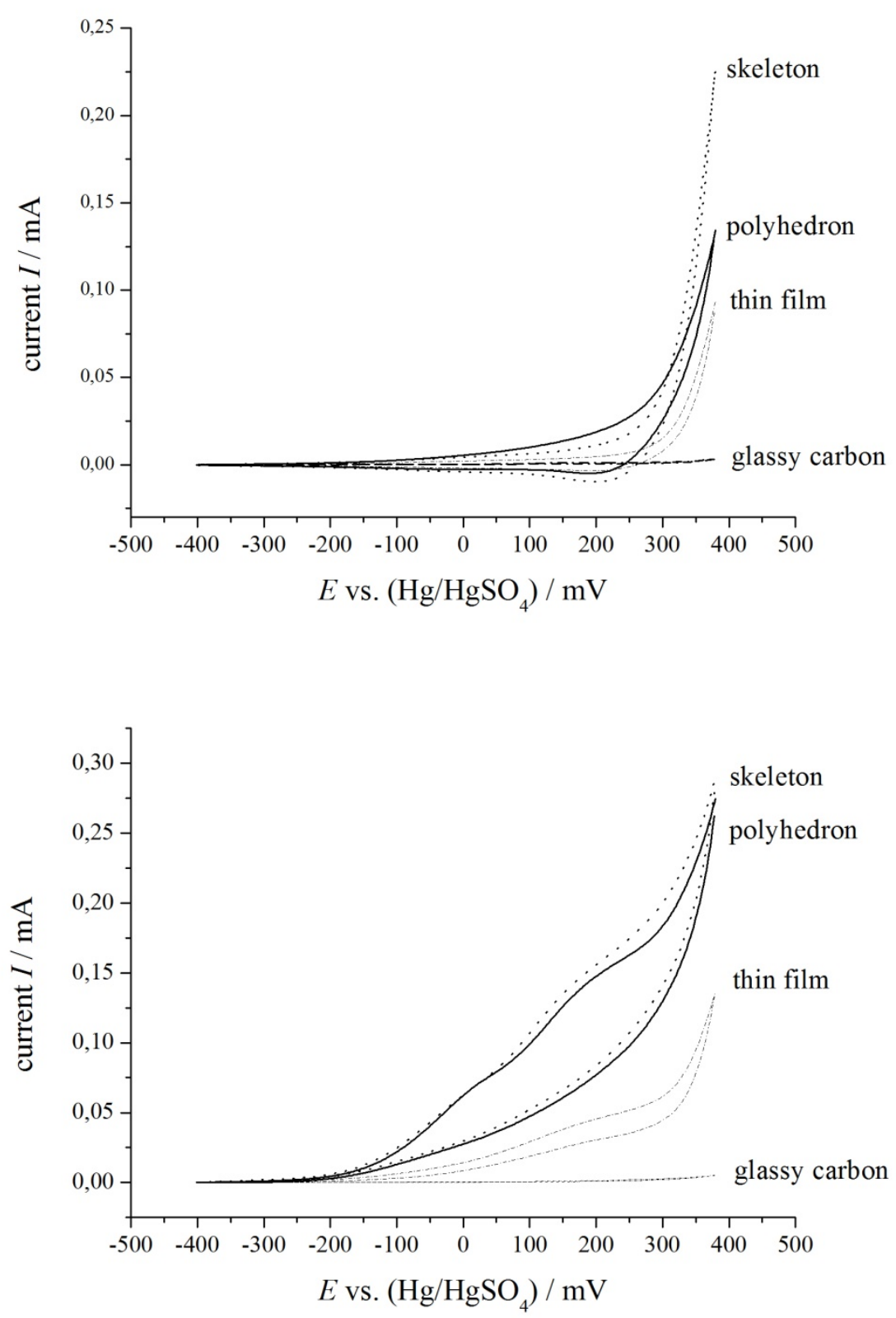

Figure 4): Cyclic voltammogram of a a) pure $100 \mathrm{mM} \mathrm{NaOH}$ solution and b) a 100nM NaOH solution containing $4 \mathrm{mM}$ glucose (continuous line: polyhedron/Nafion ${ }^{\circledR}$, dot line: skeleton/ $/ \mathrm{Nafion}^{\circledR}$, dashed line: thin film, dot-dashed line: glassy carbon), third running cycle is depicted 


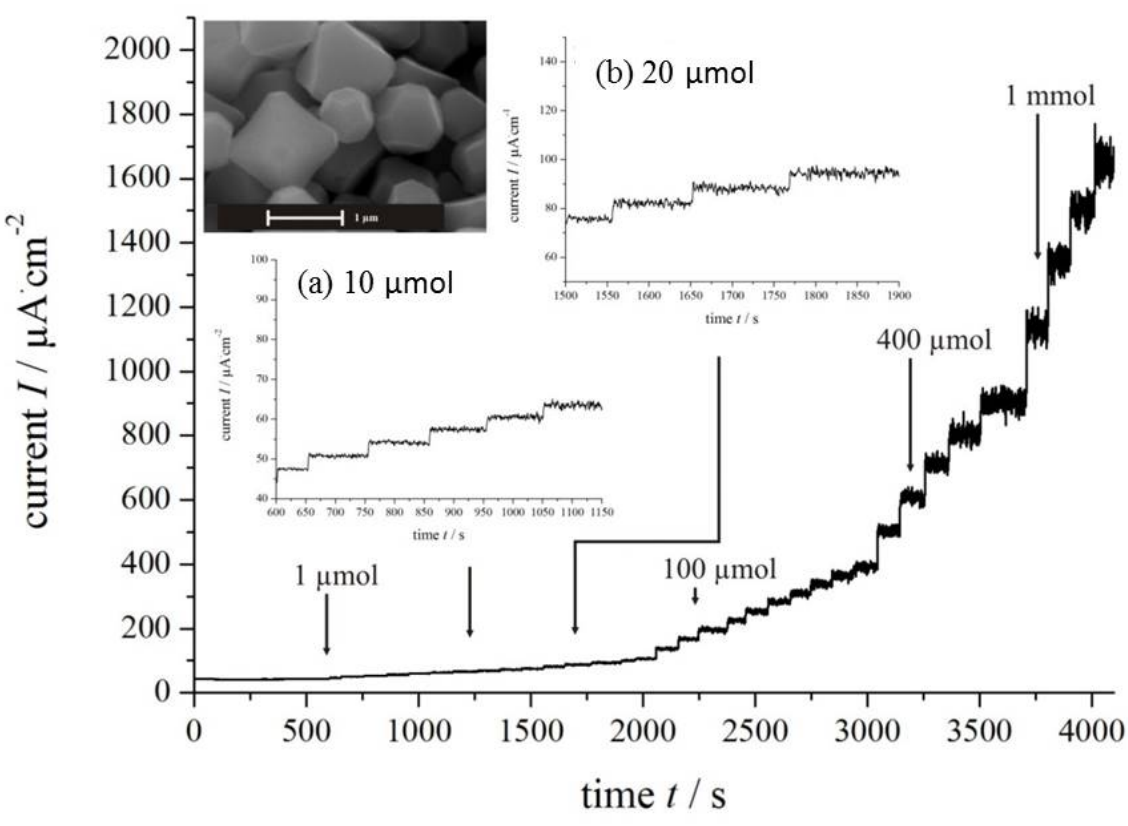

Figure 5): Response curve of polyhedron/Nafion ${ }^{\circledR}$ catalyst for successive addition of glucose starting from a concentration of $1 \mu \mathrm{mol}$ to $1 \mathrm{mmol}$

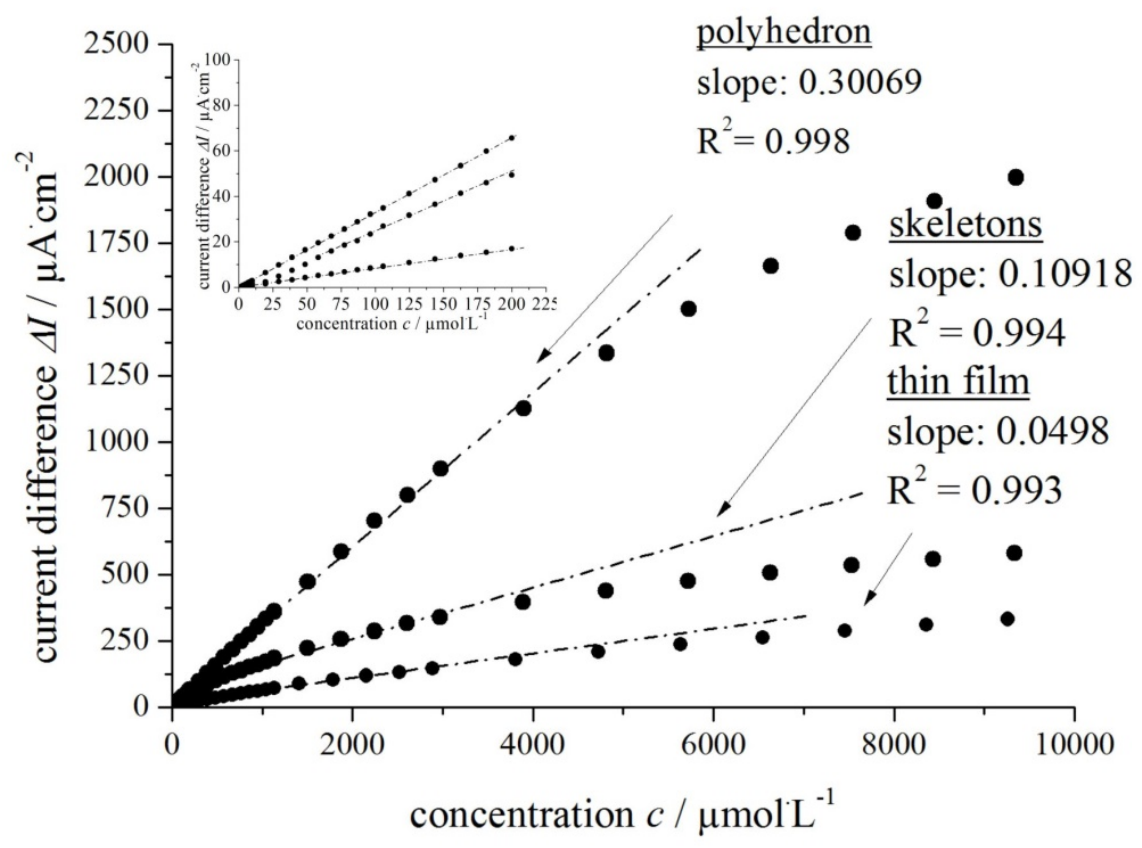

Figure 6): Calibration curves for polyhedron/ $/ \mathrm{Nafion}^{\circledR}$, skeleton/ $\mathrm{Nafion}{ }^{\circledR}$ and thin film catalysts: Polyhedron/Nafion ${ }^{\circledR}$ catalyst showed the highest sensitivity of $49.8 \mu \mathrm{A} \mathrm{mmol}^{-1} \mathrm{~cm}^{-2}$ in a linear range from $29.5 \mu \mathrm{mol} \cdot \mathrm{L}^{-1}$ to $252.9 \mu \mathrm{mol} \cdot \mathrm{L}^{-1}$ 
(a) skeleton/Nafion
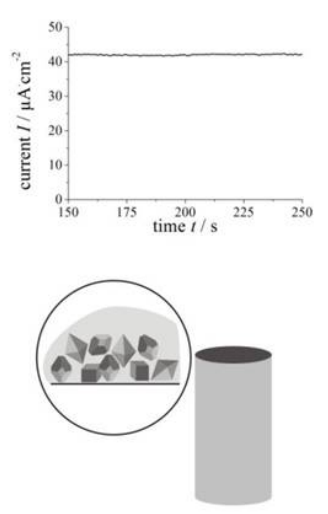

(b) skeleton/Nafion
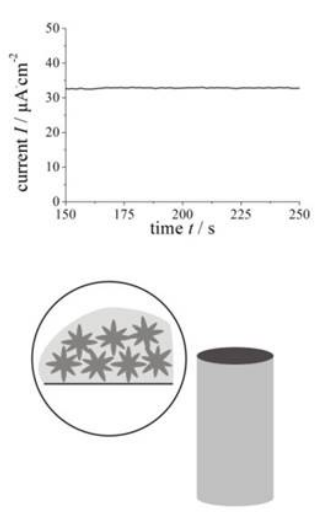

(c) thin film
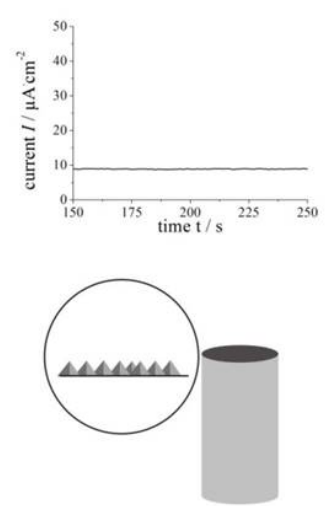

(d) thin film/Nafion
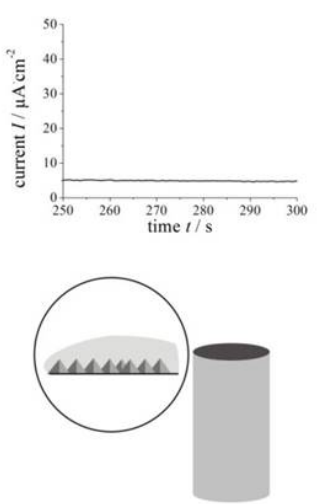

Figure 7): Ground lines of polyhedron/Nafion ${ }^{\circledR}$, skeleton/Nafion ${ }^{\circledR}$, thin film, and thin film/Nafion ${ }^{\circledR}$ (from left to right)

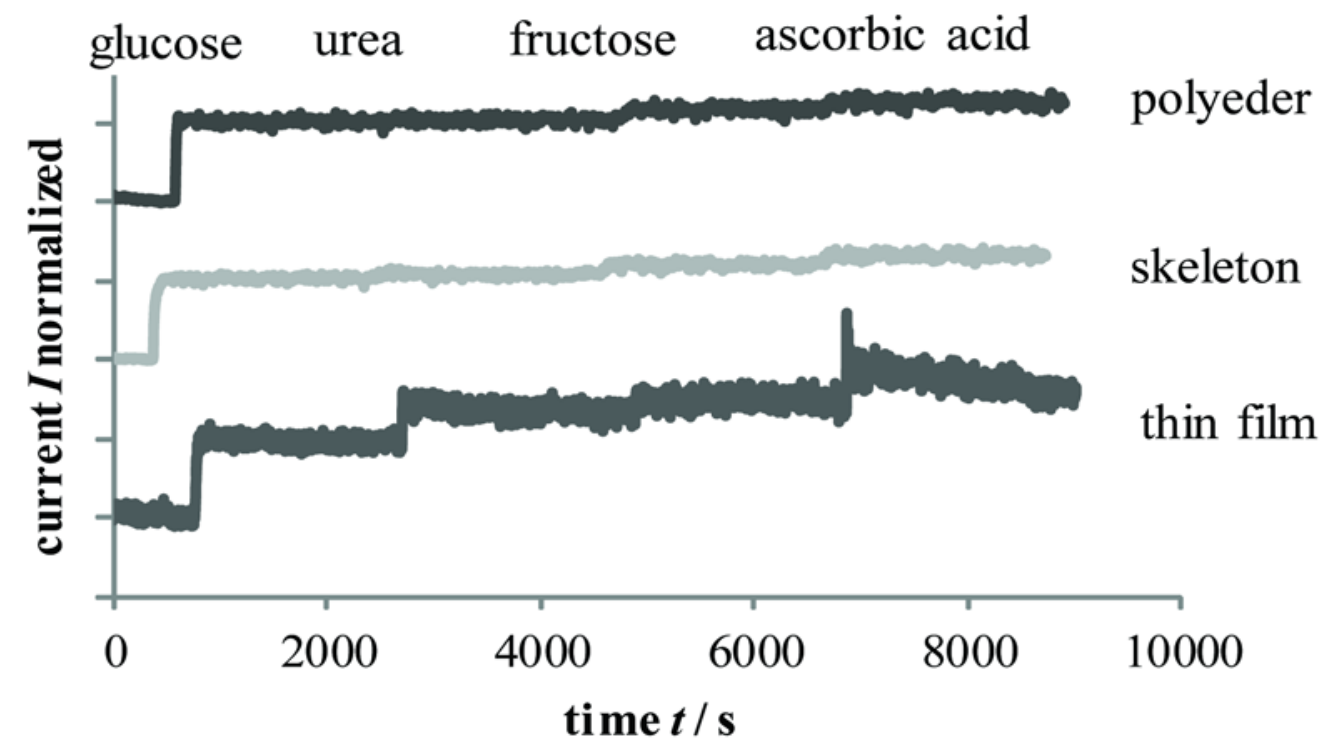

Figure 8): Current response curves for successive addition of glucose (100 $\mu \mathrm{mol})$, urea, fructose, ascorbic acid (each $10 \mu \mathrm{mol}$ ) for polyhedron/Nafion ${ }^{\circledR}$, skeleton/Nafion ${ }^{\circledR}$ and the thin film catalysts (note: curves were normalized with respect to the current increase after glucose addition) 
Table 1): Determined values of sensitivity, linear range and limit of detection LOD for cuprous oxide skeleton/Nafion ${ }^{\circledR}$, polyhedron/Nafion ${ }^{\circledR}$ and thin film catalysts in comparison to literature data

\begin{tabular}{|c|c|c|c|c|c|c|}
\hline catalyst & $\begin{array}{c}\text { detection } \\
\text { potential / } \\
\text { V }\end{array}$ & $\begin{array}{c}\text { linear } \\
\text { range / } \\
\mu \mathrm{mol} \cdot \mathrm{L}^{-1}\end{array}$ & $\begin{array}{c}\text { sensitivity / } \\
\mu \mathrm{A} \cdot \mathrm{mmol}^{-} \\
{ }^{1}{ }^{-} \mathrm{cm}^{-2}\end{array}$ & $\begin{array}{l}\text { response } \\
\text { time / s }\end{array}$ & $\begin{array}{c}\text { detection } \\
\text { limit / } \\
\mu \mathrm{mol} \cdot \mathrm{L}^{-1}\end{array}$ & reference \\
\hline polyhedron/Nafion & $\begin{array}{c}0.25 \\
\mathrm{Hg} / \mathrm{HgSO}_{4}\end{array}$ & $\begin{array}{l}1.2- \\
298\end{array}$ & 300.96 & 4 & 0.144 & $\begin{array}{c}\text { present } \\
\text { work }\end{array}$ \\
\hline \multirow[b]{2}{*}{ Skeleton/Nafion } & \multirow{2}{*}{$\begin{array}{c}0.25 \\
\mathrm{Hg} / \mathrm{HgSO}_{4}\end{array}$} & $2.9-20$ & 262.28 & \multirow[b]{2}{*}{3} & \multirow[b]{2}{*}{0.564} & \multirow{2}{*}{$\begin{array}{l}\text { present } \\
\text { work }\end{array}$} \\
\hline & & $\begin{array}{l}57.7- \\
224\end{array}$ & 109.18 & & & \\
\hline Thin film & $\begin{array}{c}0.25 \\
\mathrm{Hg} / \mathrm{HgSO}_{4}\end{array}$ & $\begin{array}{c}29.5- \\
381\end{array}$ & 49.8 & 3 & 19.48 & $\begin{array}{l}\text { present } \\
\text { work }\end{array}$ \\
\hline $\mathrm{Cu}_{2} \mathrm{O} /$ graphene/Nafion & $\begin{array}{c}0.6 \text { vs. } \\
\mathrm{Ag} / \mathrm{AgCl}\end{array}$ & $\begin{array}{l}50- \\
6750\end{array}$ & 62.27 & - & 0.037 & [39] \\
\hline $\mathrm{Cu}_{2} \mathrm{O} / \mathrm{MWCNT} /$ Nafion & $\begin{array}{l}-0.2 \mathrm{vs} \\
\text { SCE }\end{array}$ & $\begin{array}{l}<10 \\
\mu \mathrm{mol}\end{array}$ & $\begin{array}{c}6.53 \\
\mu \mathrm{A} \cdot \mathrm{mmol}^{-1}\end{array}$ & - & 0.05 & {$[40]$} \\
\hline $\mathrm{Cu}_{2} \mathrm{O}$ cubes/Nafion & $\begin{array}{c}0.6 \text { vs } \\
\mathrm{Ag} / \mathrm{AgCl}\end{array}$ & $\begin{array}{l}<0.5 \\
\text { mmol }\end{array}$ & $\begin{array}{c}121.7 \\
\mu \mathrm{A} \cdot \mathrm{mmol}^{-1}\end{array}$ & $<5$ & 38 & {$[41]$} \\
\hline $\begin{array}{c}\mathrm{Cu}_{2} \mathrm{O} \\
\text { nanospheres/Nafion }\end{array}$ & $\begin{array}{c}0.6 \text { vs. } \\
\text { Ag/AgCl }\end{array}$ & $\begin{array}{l}<0.5 \\
\text { mmol }\end{array}$ & $\begin{array}{c}185 \\
\mu \mathrm{A} \cdot \mathrm{mmol}^{-1}\end{array}$ & 3 & 0.05 & {$[42]$} \\
\hline $\begin{array}{c}\text { Cu2O/Carbon Vulcan } \\
\text { XC-72/Nafion }\end{array}$ & $\begin{array}{l}\text { 0,75 vs. } \\
\mathrm{Hg} / \mathrm{HgO}\end{array}$ & $<0.5$ & 629 & - & 2.4 & {$[43]$} \\
\hline
\end{tabular}

